\title{
The shape of inhibitory fields in the human visual system ${ }^{1}$
}

\author{
K. M. SCHOENBERG, M. KATZ, AND M. S. MAYZNER ${ }^{2}$ \\ NEW YORK UNIVERSTTY
}

\begin{abstract}
Five point sources of light were displayed sequentially in a horizontal line, with $.45 \mathrm{in}$. of separation between each point, employing a computer-based cathode-ray tube display system. If a particular display order and appropriate display rate is employed, then the first two points being displayed will not be perceived. By systematically varying the spatial location of these two blanked points relative to the three unblanked points, a start is made towards mapping the shape of visual inhibitory fields in man, and this general technique is related to the work of Hartline and of Ratliff on lateral inhibition and to that of Hubel and Wiesel with receptive fields in the cat and monkey striate cortex.
\end{abstract}

In three germinal papers concerned with the physiological analysis of inhibitory mechanisms in the visual system, Hartline $(1940 a, b, c)$ measured the receptive fields of single optic fibers of the frog by employing very small spots of light to locate that portion of a frog's retina where light stimuli would propagate impulses in the nerve fiber. This general technique was extended further in the work of Kuffler (1953) with the cat's retina and in Barlow's (1953) work with the frog's retina. More recently, Ratliff (1965) and Békésy (1967) have provided elegant summaries on a whole spectrum of sensory inhibitory mechanisms.

In the present study, point light sources are employed to stimulate the human visual system, using a spatio-temporal input pattern known to produce strong inhibitory effects, which we have previously alluded to as sequential-blanking phenomena (Bell, Forster, Finnegan, Katz, LaSusa, \& Mayzner, 1969; Buchsbaum \& Mayzner, 1969; Mayzner \& Tresselt, 1969, in press; Mayzner, Tresselt, \& Cohen, 1966; Mayzner, Tresselt, \& Helfer, 1967a, b). In sequential blanking, if appropriate spatio-temporal input configurations are employed, up to $50 \%$ of these input configurations, which may involve as many as 100 sequentially displayed inputs, may be inhibited or not perceived. In a previous paper (Mayzner \& Tresselt, in press), complex interactions between excitatory and inhibitory fields in the visual system were postulated to account for such massive inhibition of the visual input. We now ask the question: "If five point sources of light are displayed sequentially, employing a spatio-temporal ordering designed to inhibit or blank two of these five point sources, and these two blanked points are then spatially moved in the interspace between the three unblanked points, what is the shape of the resultant inhibitory field?" In effect, we are moving, in space, the point light sources that impinge on the S's retina, analogous to the technique of Hartline, Kuffler, Barlow, etc.; and rather than measuring impulses in nerve fibers as indices of excitatory and inhibitory field interactions, we are indexing such interactions to the S's psychophysical reports of the presence or absence of certain specific inputs in the total input array.

\section{Subjects}

Two male undergraduate students at the University Heights campus of New York University served as Ss. Both Ss were well practiced in the type of psychophysical judgments required of them in this study.

\section{Apparatus}

The stimuli were presented on two Fairchild cathode-ray tube (CRT) display consoles simultaneously, both slaved to a 340 Master Display, driven by a PDP-7 digital computer. A complete description of this hardware system and its associated computer programs (software) may be found in previous publications (Mayzner, 1968; Mayzner, Tresselt, \& Helfer, 1967a).

\section{Materials}

The basic stimulus configuration selected for study consisted of five point light sources presented sequentially in a display order known to produce strong sequential-blanking effects (Mayzner, Tresselt, \& Helfer, 1967b). The diameter of each point light source was approximately $.01 \mathrm{in}$. and had a display luminance of $1 \mathrm{~mL}$, as measured with a Gamma Scientific photometric system (Model 2020EA). In the basic display configuration, the point sources were displayed in a single horizontal line, with .45 in. of separation between each point. The display order was 31425 , i.e., the second point in the line (Display Location 2) was displayed first, the fourth point in the line (Display Location 4) was displayed second, the first point in the line
(Display Location 1) was displayed third, etc. Each point was displayed for $20 \mathrm{msec}$, and there was an interstimulus interval (ISI) between points of $20 \mathrm{msec}$, since this input timing had previously been shown to maximize sequential blanking (Mayzner, Tresselt, \& Helfer, 1967b), i.e., the points displayed first and second are not reported as being perceived if the distance between them is not too great. Pilot work had shown that, with the $.45 \mathrm{in}$. of separation selected, Ss rarely, if ever, reported "seeing" more than three points, i.e., the two end points and the middle point, when $S$ was positioned $36 \mathrm{in}$. directly in front of the CRT display console. It should be noted, however, that if the input rate is $5 \mathrm{msec}$ on $/ 5 \mathrm{msec}$ off per input, then all five inputs are always clearly perceived and as occurring simultaneously.

With this basic 20-msec-on/20-msec-off display configuration constructed and known to produce reports of only three points being perceived when, in fact, five points were being displayed, over 100 additional display configurations were constructed, in which the two blanked points, i.e., the points displayed first and second, were systematically moved to a large number of different spatial locations in the interspace between and around the three unblanked points. Table 1 presents a small sample of such displays.

Table 2 gives, in diagrammatic form, a portion of all of the 119 displays examined in the study, with the two " $+\mathrm{s}$ " representing the point sources displayed third and fourth (fixed in location), while the " $O$ " (allowed to move in the interspace) represents the point sources displayed first. The points displayed second and fifth, to the right of the three points shown, are not given in Table 2 because of their symmetry with the points on the left side of the display. The 118 periods in Table 2 represent all of the different spatial locations where the point source displayed first was located, in addition to the basic location at " $O$," in mapping the interspace between and around the fixed point sources displayed third and fourth. The point source represented by " $O$ " in Table 2 and displayed first and a second point source (not shown and to the right) displayed second successively occupied in a symmetrical fashion all of the 118 spatial locations in the interspace, indicated by 
Table 1

A Small Sample of the Displays Employed in the Study

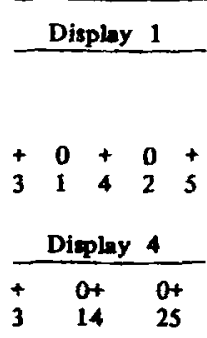

\begin{tabular}{cc} 
& Display 2 \\
\hline 0 & 0 \\
1 & 2
\end{tabular}

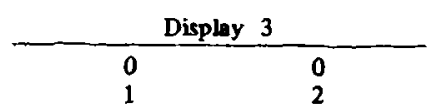

\section{$+$}

3

$$
+
$$

$+$

\begin{tabular}{llll}
\multicolumn{4}{c}{ Display 5} \\
\hline $\begin{array}{l}3 \\
0\end{array}$ & + & & 5 \\
1 & & 0 & 5 \\
& & &
\end{tabular}

had seen. These were as follows: (1) "I see three points, equally spaced"; (2) "I see three points, but there appears to be some type of movement involved, in which the points represent the termini of this movement"; and (3) "I see five points." Very infrequently did a $S$ report seeing 5 four points, but since this event was so rare, i.e., much less than $1 \%$ of the total responses, it was scored as a fivo-point response. Since pilot work had so conclusively established these different response categories, and since the two Ss of this study in their practice trials also spontaneously reported in terms of these categories, each $\mathrm{S}$ was asked to write on his response sheet, for each of the 1,190 trials, a "3," a "3M," a "4" (a very rare occurrence), or a " 5 ." The total number of each of these different responses for the Ss became the basic dependent response measures of the study.

\section{RESULTS AND DISCUSSION}

Table 2 shows, in addition to a diagrammatic scheme of the display locations examined in the study, three numbers under each period or point light source location. The first number refers to the number of reports of " 3, " i.e., $\mathbf{S}$ saw three points only; the second number refers to the number of reports of "3M," i.e., $S$ saw three points only but with phi-like movement; the third number refers to the number of reports of " 4 " or " 5 ," i.e., $S$ saw four or five points. The set of three numbers under each period always sums to 20 (i.e., 2 Ss by 10 trials), and the last column of Table 2 (labeled "Totals") sums the figures across each row for the three response categories.

A large number of additional test trials also were run, where certain point light sources were quite close to one another, i.e., only .09 in. or .18 in. apart, but at an (diam $=.25$ in.), one directly above the separated by $2.16 \mathrm{in}$. and the middle point distributed over three testing sessions on 3 separate days. For each of the 10 trials, the 119 displays were presented in a different random order.

Preliminary pilot work had established that with the display configurations under study, only three basic responses were given when $S$ was asked to report what he

Table 2

Diagrammatic Scheme of the Display Lacations and the Ss' Responses at Each Location

\begin{tabular}{|c|c|c|c|c|c|c|c|c|c|c|c|}
\hline $0-0-20$ & $0-\dot{2}-18$ & $0-4-16$ & $0:-16$ & $0-\dot{8}-12$ & $0-\dot{2}-18$ & $1-\dot{8}-11$ & $0-10-10$ & $0 \dot{9-11}$ & $2-\dot{9}-9$ & $0-6-14$ & $3-62-155$ \\
\hline $0-4-16$ & $0-2.18$ & $0-\dot{s}-15$ & $0-\dot{9}-11$ & $0-4-16$ & $0-4-16$ & $0-11-9$ & $2 \cdot \dot{6}-12$ & $0.11-9$ & $0-11-9$ & $1-11-8$ & 3-78-139 \\
\hline $1-2-17$ & $3-10-7$ & $1-\dot{9}-10$ & $2-11-7$ & $7-10-3$ & $2-i-11$ & $8-\dot{9}-3$ & $6-12-2$ & $0-18-2$ & $5-12-3$ & $2-14-4$ & $37-114-69$ \\
\hline $7 \dot{6}-7$ & $15-14$ & $15-4-1$ & 7-io-3 & $16-3-1$ & $10-7-3$ & $15-5-0$ & $9-7-4$ & $16-3-1$ & $17-2-1$ & $6-i 2-2$ & $133-60-27$ \\
\hline $15-2-3$ & $18-2-0$ & 19-1-10 & $19-1-0$ & $200-0$ & $20-0-0$ & $200-0$ & $19-1-0$ & $20-0-0$ & $20-0-0$ & $19-10$ & $209-8-3$ \\
\hline & $200-0$ & $200-0$ & $20-0$ & $20^{\circ}-0$ & $\ddot{200-0}$ & $20-0-0$ & $200-0$ & $20-0-0$ & $20-0-0$ & & $180-0-0$ \\
\hline $18-20$ & $17-3-0$ & $18-2-0$ & 2000 & 20000 & 2000 & $19-0-1$ & $20^{\circ} 0-0$ & $20-0-0$ & $20-0$ & $20-00$ & $212-7-1$ \\
\hline $14-4-2$ & $10-7-3$ & $15 \cdot 3-2$ & $1-15-4$ & $15-2-3$ & $7-6-7$ & $18-2-0$ & $1 \dot{1-6-3}$ & $19-1-0$ & $20-0-0$ & $18-2-0$ & $148-48-24$ \\
\hline $3-9-8$ & $3-\dot{9}-8$ & $0-6-14$ & 4-9-7 & $7-i 2-1$ & $2-9-9$ & $6-i 3-1$ & $12-7-1$ & $3-9-8$ & 8-i1-1 & $5-i 4-1$ & $53-108-59$ \\
\hline 4.2-14 & $0-3-17$ & $3-6-11$ & 0.13 .7 & $0-\dot{9}-11$ & $0-\dot{2}-18$ & $1-7-12$ & $1-19-0$ & $3-14-3$ & $4-7-9$ & $3-i 6-1$ & $19-98-103$ \\
\hline $0.2-18$ & $1-3-16$ & $1-\dot{7}-12$ & $a-6-14$ & $0 \div-13$ & $04-16$ & $0-4-16$ & 1.i7.2 & $1-i s-4$ & s-i2-3 & $0-6-14$ & $9-93-118$ \\
\hline
\end{tabular}


input rate of $5 \mathrm{msec}$ on $/ 5 \mathrm{msec}$ off. Under these conditions, both Ss always reported seeing five points, and therefore, the sequential-blanking effects shown in Table 2 can be attributed to the input timing employed, i.e., $20 \mathrm{msec}$ on $/ 20 \mathrm{msec}$ off, rather than to any inability of $S$ s to successfully discriminate the point light sources in those configurations in which the point sources were spatially very close to one another.

Certain trends are clearly evident in Table 2. First, in the single horizontal line configuration, where all point sources fall on the same line, total blanking of the points displayed first and second occurs, and for the two lines, one immediately above and one immediately below this center line, blanking is almost $100 \%$. This result is particularly evident in the figures shown in the "Totals" column at the extreme left of Table 2 . Second, the next two lines, above and below, begin to show, in the figures given in the body of the table as well as in the "Totals" column, an increasing decline in the sequential-blanking effect, increasing reports of three points but with phi-like movement involved, and increasing reports of five points, and this trend accelerates further as one moves still higher or lower from the middle-line position. Since the extreme top and bottom lines failed to yield $100 \%$ reports of five points present, the entire study was replicated with two additional Ss and two extra lines of points added both above and below the top and bottom lines shown in Table 2 . These results were in complete agreement with those shown in Table 2, increasing our confidence in the shape of the inhibitory fields revealed in Table 2 . Further, at the extreme distance above and below the middle line, i.e., .63 in., the values corresponding to those shown in the "Totals" column of Table 2 were 0-12-208 for the extreme top line and 0-9-211 for the extreme bottom line, thus clearly demonstrating that, at this distance, the inhibitory field effects of the three blanking points is essentially totally eliminated.

We have discussed in some detail the theoretical mechanisms we believe respotisible for the sequential-blanking or inhibitory-field effects shown in Table 2 (Mayznex \& Tresselt, in press) and will not repeat them here. What is new in the present study is the actual shape of the inhibitory field established by the three fixed blanking points, when the input order of all five points is 31425 . It appears obvious from an examination of Table 2 that the inhibitory field has the character of a series of rectangular bands; the first band extends about .09 in. above and below the middle line of points, the second band extends from about .09 in. above and below the first band to about .27 in., and a third band extends beyond this until, at about .63 in. above the middle line of points, all inhibitory effects are dissipated. Such rectangular bands raise the interesting speculation that they may in some functional sense correspond to the rectangular columnar system suggested by Hubel and Wiesel $(1959,1962,1968)$ as constituting a fundamental structure within the striate cortex of the cat and monkey and which we have previously alluded to also as representing a basic processing component in sequential-blanking effects (Buchsbaum \& Mayzner, 1969; Mayzner \& Tresselt, 1969, in press; Mayzner, Tresselt, \& Helfer, 1967b)-effects resulting from excitatory and inhibitory field interactions.

It would obviously be premature at this time to accept the preceding analysis without some caution. However, the general methodological strategy, introduced in this study, of employing point light sources to map the shape of inhibitory fields in the human visual system appears promising, and by varying the number of point light sources, their display luminance, their spatial locations, and their input order and timing, it should now prove possible to gain a clearer picture or mapping of the actual shape of inhibitory fields in man's visual system than has been done heretofore. One also begins to wonder to what degree the shape of such inhibitory fields may vary as a function of the size and/or shape of the inputs employed to accomplish the mapping function.

\section{REFERENCES}

BARLOW, H. B. Summation and inhibition in the frog's retina. Joumal of Physiology, 1953, $119,69-88$.

BÉKÉSY, G. von. Sensory inhibition. Princeton, N.J: Princeton University Press, 1967.

BELL, A., FORSTER, R. G., FINNEGAN, F. J. KATZ, M., LASUSA, J. I., \& MA YZNER, M. S. Sequential blanking and visual form perception. Psychonomic Science, 1969, 15, 103-104.

BUCHSBAUM, W. H., MAYZNER, M. S. The effects of line length on sequential blanking. Prychonomic Science, 1969, 15, 111-112.

HARTLINE, H. K. The nerve mesarges in the fibers of the vioual pathway. Joumal of the Optical Society of America, 1940a, 30, $239-247$.

HARTLINE, $H . K$. The receptive fields of optic nerve fibers. American Journal of Physiology, $1940 b, 130,690-699$.

HARTLINE, H. K. The effects of spatial summation in the retine on the excitation of the fibers in the optic nerve. American Journal of Physiology, 1940c, 130, 700-711.

HUBEL, D. H., \& WIESEL, T. N. Receptive fields of single neurones in the cat's striate cortex. Jound of Physioloty, 1959, 148, 574-596.

HUBEL, D. H., WIESEL, T. N. Receptive fields, binocular interaction, and functional architecture in the cat's visual cortex. Journal of Physiology, 1962, 160, 106-123.

HUBEL, D. H., \& WIESEL, T. N. Receptive fields and functional architecture of monkey striate cortex. Journal of Physiology, 1968, 195, 215-243.

KUFFLER, S. W. Discharge patterns and functional organization of mammalian retina. Journal of Neurophysiology, 1953, 16, 37-68. MAYZNER, M. S. The research poteritial of a computer-based cathode-ray tube display system. Behaviar Research Methods \& Instrumentation, 1968, 1, 41-43.

MAYZNER, M. S., \& TRESSELT, M. E. Sequential blanking: A function of geometric analyzers in the humen visual system. Psychonomic Science, 1969, 17, 77-78.

MAYZNER, M. S., \& TRESSELT, M. E. Visual information processing with sequential inputs: A general model for sequential blanking, displacement, and overprinting phenomena. Annals of the New York Academy of Sciences, in press.

MAYZNER, M. S., TRESSELT, M. E., \& COHEN, A. Preliminary findings on some effects of very fast sequential input rates on perception. Psychonomic Science, 1966, 6. 513-514.

MAYZNER, M. S., TRESSELT, M. E., \& HELFER, M. S. A research strategy for studying certain effects of very fast sequential input rates on perception. Psychonomic Monograph Supplements, 1967a, 2(5, Whole No. 21), 73-81.

MAYZNER, M. S., TRESSELT, M. E., \& HELFER, M. S. A provisional model of visual information procesaing with sequential inputs. Psychonomic Monograph Supplements, 1967b, 2(7, Whole No. 23), 91-108.

RATLIFF, F. Mech bands: Ouantitative studies on neural networks in the retina San Francisco: Holden-Day, 1965.

\section{NOTES}

1. This research was supported by Grant No. GB-8037 from the National Science Foundation to the last euthor.

2. Address: 15 Sydney Avenue, Deal, New Jersey 07723.

(Accepted for publication September 30, 1969.) 